\title{
Sulphasalazine and lung toxicity
}

\author{
S.D. Parry, C. Barbatzas, E.T. Peel, J.R. Barton
}

\begin{abstract}
Sulphasalazine and lung toxicity. S.D. Parry, C. Barbatzas, E.T. Peel, J.R. Barton. (C) ERS Journals Ltd 2002.

ABSTRACT: Sulphasalazine prescribing is on the increase. Pulmonary toxicity and blood dyscrasias are rare side-effects. Numerous case reports have been published implicating sulphasalazine in pulmonary toxicity. The authors searched the literature for cases of sulphasalazine induced lung toxicity and the 50 cases identified are discussed here.

All published case reports/letters referring to sulphasalazine and lung toxicity were studied. The search terms "sulphasalazine" and "sulfasalazine" were combined with the terms "lung", "pulmonary disease", "pneumonitis" and "pleuritis" using Medline and PubMed databases.

Typical presentation of sulphasalazine-induced lung disease was with new onset dyspnoea and infiltrates on chest radiography. Common symptoms were cough and fever. Crepitations on auscultation and peripheral eosinophilia were noted in half of the cases. Sputum production, allergy history, rash, chest pain and weight loss were inconsistent findings. Pulmonary pathology was variable, the commonest being eosinophilic pneumonia with peripheral eosinophilia and interstitial inflammation with or without fibrosis. Fatal reports were infrequent. Most patients were managed by drug withdrawal with $40 \%$ prescribed corticosteroids.

In conclusion, sulphasalazine lung disease should be distinguished from interstitial lung disease due to underlying primary disease. Despite the increase in sulphasalazine prescribing, pulmonary toxicity remains rare. The majority of patients with suspected sulphasalazine-induced lung disease improved within weeks of drug withdrawal and the need for corticosteroids is debatable.
\end{abstract}

Eur Respir J 2002; 19: 756-764.

Northumbria Division, University of Newcastle Faculty of Medicine, North Tyneside Hospital, North Shields, UK.

Correspondence: E.T. Peel, University of Newcastle Faculty of Medicine, North Tyneside General Hospital, Rake Lane, North Shields, NE29 8NH, UK.

Fax: 441912932722

E-mail: Tim.Peel@

northumbria-healthcare.nhs.uk

Keywords: Adverse drug reaction lung

pulmonary disease

sulphasalazine

\section{Received: August 12001}

Accepted after revision November 5 2001
Sulphasalazine has been used worldwide since the 1940 's when it was first prescribed for ulcerative colitis. Its use in the management of inflammatory bowel disease (IBD) is declining with the availability of newer nonsulphur containing aminosalicylates. Conversely, its use as a disease-modifying antirheumatoid drug (DMARD) in the treatment of rheumatoid arthritis is well known [1], its pattern of prescribing by rheumatologists is changing with the development of combination therapies and earlier prescribing of DMARD's in the course of the disease $[2,3]$. Overall prescribing of sulphasalazine is on the increase. Information provided from the statistics division $1 \mathrm{E}$ of the Department of Health shows that in the decade 1980-1990 there were 4.3 million prescriptions for sulphasalazine with 652 million tablets prescribed. In the last decade to 1998 there were 4.6 million prescriptions with 698 million tablets prescribed.

Sulphasalazine has clinically important side-effects in up to one-fifth of patients but these are mostly nausea and vomiting, skin rashes, arthralgia, fever and hepatic dysfunction. More serious side-effects include pulmonary toxicity and blood dyscrasias. Early case reports of adverse effects were published in the 1960's [4] and knowledge of adverse pulmonary effects is not new [5-7]. Numerous case reports have been published in the last 30 yrs implicating sulphasalazine in pulmonary toxicity. The present authors searched the literature and identified 48 reports (50 patients) of possible sulphasalazine-induced lung toxicity. The majority of these reports provide convincing evidence that sulphasalazine is implicated in the adverse pulmonary reaction.

This article comments on the overall findings of these case reports including the profiles of fatal outcomes. A brief discussion on pulmonary disease associated with IBD is provided and a breakdown of the UK fatal-toxicity reports obtained from the Medicine Control Agency for sulphasalazine over the last 36 yrs is shown. Finally, the conclusions of the findings with respect to the management of sulphasalazine induced pulmonary toxicity and the safety of sulphasalazine relative to its prescribing are discussed.

\section{Materials and methods}

\section{Study subjects}

The retrospective case study involved all patients in published reports between 1972-1999 who were taking sulphasalazine and who had developed a possible adverse reaction to the drug. 


\section{Methods}

All published case reports/letters referring to sulphasalazine and lung toxicity were identified from the databases Medline and PubMed. The search terms "sulphasalazine" and "sulfasalazine" were combined with the terms "lung", "pulmonary disease", "pneumonitis" and "pleuritis". Information on 50 patients (48 reports), 17 female and 33 male, was found in the literature between 1972-1999 [8-54].

One case [55] not found on the databases was uncovered during the course of this study and included. Another possible case described in a letter [56] is not included because no details were given. The demographics of the case population, the diagnosis of the underlying disease, the dose of sulphasalazine prescribed, the duration of exposure to the drug, the presenting features, laboratory investigations, radiological and histocytopathology findings and the management and eventual outcome of the likely adverse event were noted.

\section{Results}

\section{Demographics}

The mean age of the patients was 48.3 yrs (range 12-88) and ulcerative colitis was the commonest underlying condition for which sulphasalazine had been prescribed (in 36 patients, 72\%). Three patients had Crohn's disease, one patient had unspecified IBD, six patients had rheumatoid arthritis, two seronegative arthritis, one Sjörgrens syndrome and one patient had been prescribed sulphasalazine for nonspecific bowel symptoms (table 1). Two of the patients had previously documented aspirin sensitivity $[19,35]$ and one of the cases had previous sulphonamide sensitivity [20].

\section{Sulphasalazine dose}

The daily dose of sulphasalazine ranged from $1-8 \mathrm{~g}$ (mean $3 \mathrm{~g}$ ) (table 1). Nine patients were receiving concurrent corticosteroids, most of them towards the end of a reducing course when their pulmonary symptoms of toxicity began. The average duration of exposure to sulphasalazine was 17.8 months with a range of $0.5-120$ months (a case where re-exposure, after an initial treatment of 12 months and a break of 7 months, caused pulmonary symptoms within a few days [17] has not been included). In a report detailing two cases [17], one was taking concurrent methotrexate. In another report the patient was on concurrent ibuprofen [48]. Both methotrexate [57, 58] and ibuprofen [59-61] have been implicated in pulmonary disease.

\section{Symptoms and signs}

The main clinical symptoms were breathlessness, present in 40 cases $(80 \%)$, fever in 35 cases $(70 \%)$ and

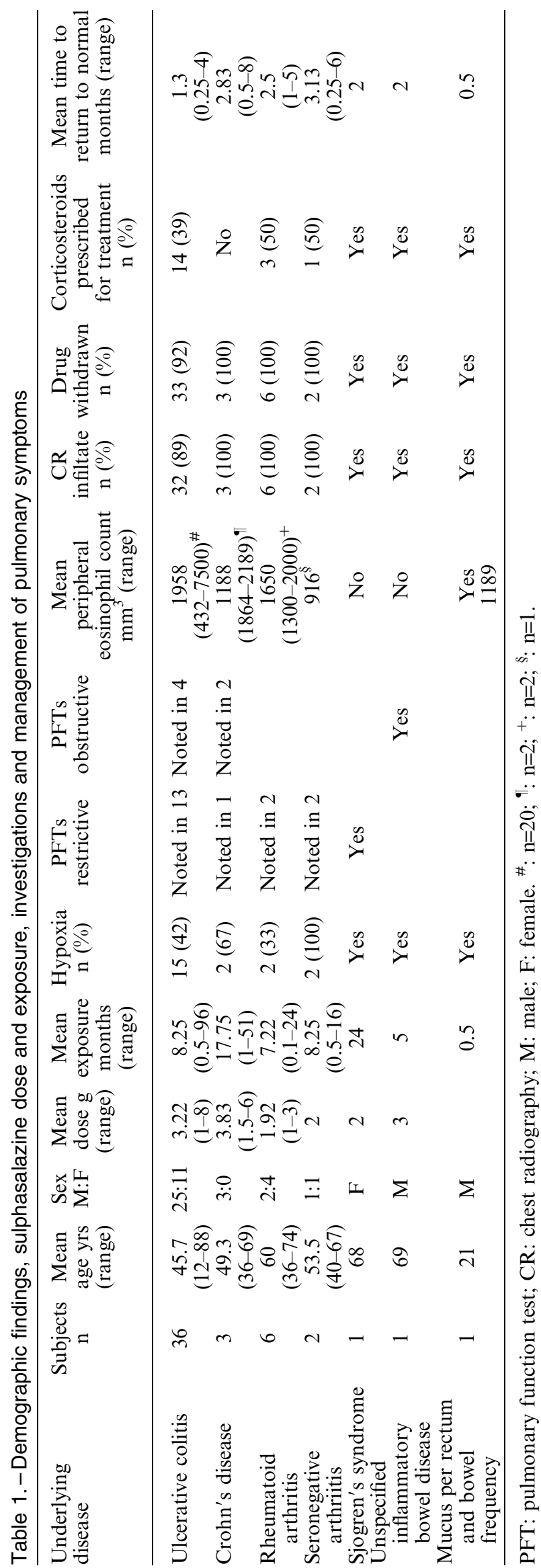


Table 2. - Summary of the main clinical features of sulphasalazine lung toxicity

\begin{tabular}{lc}
\hline $\begin{array}{l}\text { Clinical symptoms signs } \\
\text { and investigations }\end{array}$ & $\begin{array}{c}\text { Number of cases } \\
\text { (out of } 50 \\
\text { unless stated) }\end{array}$ \\
\hline
\end{tabular}

\begin{tabular}{lcc} 
Breathlessness & 40 & 80 \\
Fever & 35 & 70 \\
Cough & 32 & 64 \\
Weight loss & 11 & 22 \\
Chest pain & 10 & 20 \\
Rash & 4 & 8 \\
Crepitations/rales/crackles & 26 & 52 \\
Abnormal chest radiograph & 50 & 100 \\
Hypoxia & $27 / 30$ & 90 \\
Abnormal lung function & $26 / 29$ & 90 \\
Restrictive lung function & $19 / 29$ & 66 \\
Obstructive lung function & $7 / 29$ & 24 \\
Peripheral eosinophilia & $26 / 48$ & 54 \\
\hline
\end{tabular}

\#: Two case reports showed both a restrictive and obstructive picture.

cough in 32 cases (64\%). Less common symptoms were weight loss, present in 11 cases, and chest pain in 10 cases. The triad of breathlessness, cough and fever was present in 21 of the 50 cases $(42 \%)$. Rash was commented on in 4 cases [16, 27, 36, 37]. One of these patients developed an initial rash and underwent desensitization with the drug only to subsequently develop a pneumonitis on re-exposure [36]. Skin pigmentation was also noted in one case [49]. Clinical signs included crackles/crepitations/rales on chest auscultation in 26 of the cases (52\%) (table 2).

\section{Laboratory investigations}

Documented peripheral eosinophilia occurred in 26 of cases $(52 \%)$ with a range varying between $432 \cdot \mathrm{mm}^{3}-7500 \cdot \mathrm{mm}^{3}$ (mean $\left.1995 \cdot \mathrm{mm}^{3}\right)$ (table 1$)$.

Hypoxia on blood gas analysis was mentioned in 27 out of 30 of the reports $(90 \%)$, including three reports where blood gas analysis was performed only after drug rechallenge $[19,26,35]$. Three cases reported normal gases $[29,41,51]$ and in the remaining cases hypoxia was not mentioned. Some element of pulmonary function testing was performed in 29 cases, and in the remaining 21 cases lung function was either not assessed or mentioned. Nineteen cases out of $29(66 \%)$ documented a restrictive deficit and $7(24 \%)$, an obstructive deficit on pulmonary function tests, with two cases showing a combined restrictive and obstructive picture [15, 18] (tables 1 and 2). In one case lung function carried out on rechallenge was obstructive [35], in another case lung function revealed diminished diffusing capacity with normal vital capacity and forced expiratory volume [49]. In three cases lung function was reported as normal [21, 29, 38].

\section{Radiology}

Chest radiographs were abnormal in all cases with the majority showing pulmonary infiltrates (46 cases or $92 \%$ ). One of these also revealed a hydropneumothorax [17]. There were reports of fine reticular shadowing in one case [14], collapse/consolidation in another case [31], an increase in interstitial markings and bronchiectasis in one case [45] and nodular interstitial markings in another case [46].

High resolution computed tomography chest scans (HRCT) were performed in only 5 cases [8, 23, 49, $51,52]$ showing typical infiltrates and ground glass opacities. Taking these cases sequentially the descriptions are as follows. In the first case the HRCT pattern was one of predominantly alveolar and ground glass opacities with air bronchograms but no pulmonary nodules were seen. In the second case the HRCT revealed multiple bilateral peripheral wedge shaped infiltrates with one of the nodules showing central cavitation. In the third case the HRCT showed patchy ground glass shadowing mainly in the middle and upper lobes. In the fourth case, the HRCT showed interstitial opacities with pleural thickening in the upper lung. Finally in the last case the HRCT showed extensive bilateral upper-lobe infiltration with areas of ground glass appearance.

\section{Histocytopathology}

Lung biopsy was performed in $40 \%$ of patients $(n=20)$. Ten patients underwent open lung biopsy, nine patients underwent transbronchial biopsy and one patient had a videothoracoscopic lung biopsy.

Bronchoalveolar lavage (BAL) was performed in 11 patients $(22 \%)$ with five demonstrating an increase in eosinophils ranging from $23 \%-69 \%$ [16, 24, 27, 30, 43]. In one of these cases there was also an increase in lymphocytes [27]. In the remaining cases, the BAL was reported as abnormal in three with elevated lymphocytes ranging from $31 \%-43 \%$ but with no increase in eosinophils $[22,23,54]$. In one case there was an increase in neutrophils only [48]. In another case no mention of the cellular differential was made [41]. In only one case where it was performed was the BAL reported as normal [51].

Final histological diagnoses varied in the literature. The common histological theme was one of interstitial pneumonitis/inflammation. Fibrosing alveolitis was diagnosed in four cases, and in another four biopsies comments were made regarding fibrosis on the histology. In 11 cases the diagnosis was of eosinophilic pneumonia/pneumonitis or pulmonary eosinophilia and in 10 of these cases lung biopsy was not performed. In addition, there were clinical diagnoses of hypersensitivity pneumonitis or sulphasalazine pneumonitis/alveolitis in seven cases. Less specific terms such as pneumopathy, sulphasalazine lung disease and pulmonary hypersensitivity reaction were also used in terms of a clinical diagnosis in a further six cases (table 3). Granulomas were seen in four cases, but it should be noted that in one of these the patient had coexistent tuberculosis [43].

Other, less common, histological diagnoses included bronchiolitis obliterans, bronchiolitis organising obliterative pneumonia and desquamative interstitial pneumonia (DIP). DIP has histological features of 
Table 3. - Diagnoses and mode of diagnoses

Underlying disease $n$

Ulcerative colitis 36

Crohn's disease 3

Rheumatoid arthritis 6

Seronegative arthritis 2

Sjorgrens syndrome 1

Unspecified inflammatory

bowel disease 1

Mucus per rectum,

bowel frequency 1

PM: post mortem; Open: open lung biopsy; C: clinical diagnosis; TBB: transbronchial biopsy; VT bx: videothorascopic biopsy; BOOP: bronchiolitis organising obliterative pneumonia.

interstitial inflammation and macrophages in airspaces, is a reaction of lung tissue to a variety of agents and is not felt to be a specific disease. Both fibrosing alveolitis and eosinophilic pneumonia are related to DIP and the histopathological differentiation between them may be difficult [62]. Further discussion regarding the various histological terms and features of interstitial lung disease are out of the scope of this article.

Rechallenge/desensitization or provocation tests were carried out in 13 cases $[11,13,18,19,21,26$, $28-30,35,37,51,55]$ and are discussed later.

\section{Management and outcome}

Clinical improvement occurred in the majority of cases $(90 \%)$ with resolution occurring within an average of six and a half weeks from initiation of management (range 1-32 weeks). Management included withdrawal of sulphasalazine in 47 cases. In the three cases where the drug was not withdrawn, two of the patients died $[10,33]$. In 20 cases $(40 \%)$ management included the addition of corticosteroids and is discussed later.

Five patients on sulphasalazine with lung symptoms died and the cause of death was due to pulmonary pathology $[10,11,33,45,46]$. All patients who died had ulcerative colitis as their underlying condition. The mean dose of sulphasalazine was $3.6 \mathrm{~g}$. In three cases the patients had been on sulphasalazine for a number of years before the onset of their pulmonary symptoms and in two of these cases, a number of years had elapsed from onset of lung symptoms to death. The drug was not withdrawn in two cases (table 4).

\section{Discussion}

The emergent and consistent themes in these reports of pulmonary disease associated with sulphasalazine, were that patients presented with new onset dyspnoea and had abnormal chest radiography. The majority of 
Table 4.-Features of fatal case reports

\begin{tabular}{|c|c|c|c|c|c|c|c|c|}
\hline $\begin{array}{l}\text { Age } \\
\text { yrs }\end{array}$ & Sex & $\begin{array}{c}\text { Underlying } \\
\text { diagnosis }\end{array}$ & $\begin{array}{c}\text { Sulphasalazine } \\
\text { dose }\end{array}$ & $\begin{array}{l}\text { Exposure to } \\
\text { sulphasalazine } \\
\text { before lung } \\
\text { symptoms }\end{array}$ & $\begin{array}{c}\text { Drug } \\
\text { withdrawn }\end{array}$ & $\begin{array}{l}\text { Time to death } \\
\text { from onset } \\
\text { of lung } \\
\text { symptoms }\end{array}$ & Cause of death & [Ref. no.] \\
\hline 47 & $\mathrm{~F}$ & Ulcerative colitis & $6 \mathrm{~g}$ & 4 months & No & 1 month & Fibrosing alveolitis & [10] \\
\hline 53 & $\mathrm{M}$ & Ulcerative colitis & $3 \mathrm{~g}$ & 3 months & Yes & 12 days & Fibrosing alveolitis & [11] \\
\hline 57 & M & Ulcerative colitis & $4 \mathrm{~g}$ & 8 yrs & No & 4 days & $\begin{array}{l}\text { Pneumonic/fibrotic } \\
\text { process lower zones }\end{array}$ & \\
\hline 12 & M & Ulcerative colitis & $35 \mathrm{mg} \cdot \mathrm{kg}^{-1} \cdot \mathrm{day}^{-1}$ & $5 \mathrm{yrs}$ & Yes & $2 \mathrm{yrs}$ & Desquamative & {$[33]$} \\
\hline 50 & $\mathrm{~F}$ & Ulcerative colitis & $1.5 \mathrm{~g}$ & $10 \mathrm{yrs}$ & Yes & $5 \mathrm{yrs}$ & Fibrosing alveolitis & [45] \\
\hline
\end{tabular}

F: female; M: male.

chest radiographs showed infiltrates. Other common symptoms were cough and fever. The symptom triad of breathlessness, cough and fever was present in just under half of the cases. Half of the patients had crepitations on chest auscultation and just over half had a peripheral eosinophilia. Inconsistent findings were sputum production, allergy history, associated rash, chest pain and weight loss. Pulmonary pathology was variable, the commonest being eosinophilic pneumonia with peripheral eosinophilia and interstitial inflammation with or without fibrosis.

\section{What is it about sulphasalazine that can cause potential adverse effects?}

Sulphasalazine is a compound of 5-aminosalicylic acid (5-ASA) and sulphapyridine joined by an azo bond. The sulphapyridine component is the carrier of the 5-ASA to the colon. The azo bond is broken down by gut organisms and the 5-ASA exerts its anti-inflammatory action whilst the sulphur moiety is slowly absorbed and excreted in the urine. Sulphapyridine is believed to be responsible for most of the hypersensitivity reactions that occur, although the salicylate component may also be implicated since aspirin has been reported in association with eosinophilic pneumonia [63], and more recently, with pulmonary oedema [64]. Therefore, it is possible that there is cross-reactivity in the two aspirin sensitive susceptible patients in this study to the aminosalicylate component of sulphasalazine [19-35]. However, the component of the drug implicated is still not known and nor is the mechanism causing pulmonary toxicity. The suggestion that both components may be responsible is supported by the different adverse reactions in the same patient to sulphasalazine and then, on later rechallenge, to sulphpyridine [26]. Further evidence that sulphapyridine is the culprit is supported in the case report describing alveolitis in a female prescribed sulphamethoxypyridazine for cicatrical pemphigoid. The patient developed dyspnoea and cough, but no peripheral eosinophilia, after 6 months. Chest radiography revealed reticulonodular shadowing. The patient's symptoms resolved in 6 months after steroid therapy and cessation of the drug [65]. In addition, there were other case reports where the patients were later managed on newer 5-aminosalicylates without further pulmonary symptoms, mesalazine in one case [28] and olsalazine in another [30]. Conversely, one case published reported mesalazine as being implicated in pneumonitis [66].

What is the evidence for drug withdrawal as soon as the diagnosis is suspected?

The evidence for drug withdrawal as soon as diagnosis is suspected can be shown by the rapid resolution of symptoms in most cases, and by the fact that in the three cases where the drug was not withdrawn, two patients died $[10,33]$. The patient that recovered was given a clinical diagnosis of reversible pulmonary disease and eosinophilia associated with sulphasalazine [44]. It should be noted that in this case where the drug was not withdrawn and there was clinical resolution of symptoms, the patient had been intermittently exposed to sulphasalazine for $3 \mathrm{yrs}$ with a further period of 2 yrs of continuous treatment before the development of symptoms. The authors considered sulphasalazine as a possible cause but felt it unlikely in view of the long time interval before exposure. It is possible that this case represents an example of pulmonary eosinophilia associated with IBD.

\section{What is the evidence for rechallenge with sulphasalazine?}

The rapid resolution of symptoms in most of the published cases after drug withdrawal points to a delayed allergic mechanism. It can be argued that rechallenge with sulphasalazine is the only way to establish causality, but rechallenge has practical and ethical implications, and in only one of the 13 cases where rechallenge or provocation tests were carried out was desensitization deemed successful [21]. In one case, rechallenge with sulphasalazine followed by a later rechallenge with the sulphapyridine component [26] was positive in both challenges. There was documentation of reduced lung volumes and transfer 
factor after the second dose of sulphasalazine. However, a more obvious clinical response to the sulphapyridine challenge occurred, with the patient spiking a fever $30 \mathrm{~min}$ after the dose and demonstrating a marked fall in ventilatory capacity with arterial hypoxia. Another case describes a challenge using only the sulphapyridine component of sulphasalazine [30]. After 3 days the patient complained of progressive dyspnoea, cough and rash. This patient was later successfully treated with olsalazine for Crohn's disease.

Provocation tests can produce a number of serious adverse effects in patients challenged and many doctors would now be reluctant to perform them in view of this. Likewise, desensitization to sulphasalazine would not be appropriate unless there were extenuating circumstances, since there are a number of alternative 5-aminosalicylates on the market for the management of IBD as well as alternative DMARDs available for the management of rheumatoid arthritis.

\section{What is the evidence for prescribing corticosteroids?}

Although the majority of patients were managed with drug withdrawal, less than half $(40 \%)$ were prescribed corticosteroids/additional corticosteroids. One patient was prescribed Transilast only (a mast cell stabilizer) [21], one patient was prescribed azathioprine [46] and another penicillamine [14] in addition to corticosteroids. Two patients were kept on maintenance corticosteroids of whom one died within 1 month [10] and the other improved over a number of days [49]. Of the patients prescribed corticosteroids for management of their pulmonary disease, $16(80 \%)$ improved, and in $13(65 \%)$ pulmonary symptoms had resolved by 2 months. In three other patients, resolution of symptoms occurred, two within 6 months and one over an unknown time period. One patient given corticosteroids did not improve and three eventually died from their pulmonary disease despite corticosteroids.

Contrasting this with the remaining patients not prescribed corticosteroids, $26(96 \%)$ improved, 18 or $67 \%$ had symptom improvement by 2 months, 6 $(22 \%)$ had improved by 6 months, two had improved over an unknown time period, and one died. In the fatal case, corticosteroids had actually been stopped because of a possible diagnosis of congestive cardiac failure [33].

It can be seen that the evidence for corticosteroids influencing the outcome of patients with suspected sulphasalazine lung toxicity is not strong.

What other conditions may mimic sulphasalazine lung disease?

Recognition of sulphasalazine pulmonary damage is important but it should be noted that whilst not common, IBD as well as rheumatoid arthritis can be complicated by pulmonary pathology which typically presents in the form of a progressive diffuse interstitial pneumonitis. Lung disease in patients with Crohn's disease has included acute alveolitis, granulomatous interstitial pneumonitis and interstitial fibrosis $[67,68]$ and in patients with ulcerative colitis, bronchitis or bronchiectasis [69-71]. The association between IBD and inflammatory lung disease is not well understood and pulmonary manifestations of IBD are still thought to be rare. In 1968, IsENBERG et al. [72] suggested that pulmonary vasculitis was an uncommon complication of ulcerative colitis. In 1971 ROGERs et al. [73] studied 1,400 patients with IBD and found 94 patients with pulmonary diagnoses. However, only six of these cases were unexplained and possibly attributable to lung disease related to IBD. Further case reports followed [74, 75] together with the publication of case series of IBD associated pulmonary disease. KRAFT et al. [76] reported six cases where the patients developed severe, unexplained, chronic bronchopulmonary disease in the form of chronic bronchitis with or without bronchiectasis, up to $13 \mathrm{yrs}$ from the onset of nonspecific colonic inflammatory disease. They found an initial correlation between the pulmonary symptoms and intestinal disease severity, except in two patients who developed overt pulmonary disease following total proctocolectomy. ButLAND et al. [77] reported seven cases with three cases developing rapidly progressive bronchiectasis within one year of proctocolectomy. Two of these cases developed in association with an exacerbation of colitis and in a further two cases a milder, limited colitis postdated the start of the lung disease. In a review article, CAmus et al. [78] noted that of the 33 cases of respiratory involvement and IBD reviewed, 23 were not on drug therapy. In 28 of the cases, the respiratory disease followed the onset of the bowel disease with eight of the cases being postcolectomy. The pattern of involvement of lung disease included airway inflammation and varied interstitial lung disease mainly bronchiolitis obliterans with organizing pneumonia and pulmonary infiltrates with eosinophilia. In the majority of the reported cases of IBD associated lung disease $(76 \%)$ corticosteroids were of benefit [78].

A further, more recent case series reported seven IBD patients with large airways disease where their respiratory symptoms followed the onset of their bowel symptoms by an average of 12 yrs [79]. Interestingly, three of the patients developed their lung symptoms after colectomy. The appearance or persistence of lung symptoms despite colectomy is unusual since extra-colonic manifestations of IBD normally improve after surgery. The pathogenesis of IBD associated lung disease is not known, but one theory is that the circulating inflammatory mediators released by the inflamed bowel affect the lung [80]. However, this theory does not hold in those cases where the lung symptoms occur after colectomy.

With regard to the fatal reports of sulphalsalazineinduced pulmonary pathology, the duration between onset of symptoms and time of death in two of the cases $[45,46]$ prompted the authors to correctly consider the possibility that the underlying disease was the cause of death rather than the drug. In addition, neither patients' lung conditions improved 
despite cessation of sulphasalazine and treatment with corticosteroids and, in one case, despite colectomy [45].

Correspondingly, BAILLIE [33] stated that a patient was atypical since the patient had been on sulphasalazine for many years. Again, in this case other diagnoses were considered.

Finally, although the clinical manifestations of IBD associated pulmonary disease are believed to be rare, perhaps the association is more common. In 1980, EADE et al. [81] compared 36 patients with IBD to a control group and found that there was a significant decrease in the diffusing capacity of the lung for carbon monoxide in the patient group. However, there was no significant decrease in the patients taking sulphasalazine compared with patients not on this drug. This suggested that it was the underlying disease, and not the drug, which accounted for the decrease in diffusion capacity. A later study reported abnormalities in pulmonary function in one-third of IBD patients, although only some of the variables appeared to be related to disease activity and smokers were included in the cohort [82].

To conclude, it appears that despite the increasing number of prescriptions for sulphasalazine per year, pulmonary toxicity remains rare and the main fatal toxicity of sulphasalazine is haematological (table 5). Fatal case reports are infrequent and of the five fatal cases described in this study, all suffered from ulcerative colitis and two died from possible underlying pulmonary disease rather than drug reaction. It is known that patients with inflammatory bowel disease or rheumatoid arthritis can develop various inflammatory lung complications. Sulphasalazine lung disease should be distinguished from interstitial lung disease due to the underlying primary disease,

Table 5.-UK Fatal Toxicity Reports for sulphalsalazine from July 1963-July 2000 (courtesy of the Medicines Control Agency)

\begin{tabular}{lcl}
\hline Toxic effect & Number & \multicolumn{1}{c}{ Notes } \\
\hline $\begin{array}{l}\text { Cardiovascular } \\
\text { Cerebrovascular }\end{array}$ & 4 & \\
$\begin{array}{l}\text { Congenital } \\
\text { malformation }\end{array}$ & 1 & \\
Haemopoetic & 42 & $\begin{array}{l}\text { 13 Agranulocytosis } \\
\text { 10 Aplastic anaemia } \\
\text { 5 Neutropenia }\end{array}$ \\
& & 5 Pancytopenia \\
& & 4 Leucopenia \\
& & 2 Platelet \\
related disorders, \\
& & 2 Bone marrow depression \\
Hepatobiliary & & 1 Folate deficiency \\
anaemia \\
Neurological & 8 & Liver failure/hepatitis \\
Neoplasms & 1 & \\
Abortions/stillbirth & 2 & \\
Respiratory & 2 & 1 Pneumonitis, \\
Skin & & 1 Pulmonary fibrosis \\
Total & 2 & Epidermal necrolysis \\
\hline
\end{tabular}

although this may not be easy. In the majority of patients with suspected sulphasalazine-induced lung disease, pulmonary symptoms will resolve completely in a few weeks upon withdrawal of the drug. The need for steroid treatment of patients with suspected sulphasalazine induced lung disease is still debatable. Ultimately the decision regarding the need for steroid therapy should be based on the severity of each individual case, the underlying pulmonary diagnosis and clinical progress.

\section{Appendix}

The authors suggestions for managing patients with suspected sulphasalazine lung are listed here. 1) Suphasalazine treatment should be stopped promptly in any patient in whom pulmonary symptoms develop (the symptom triad of breathlessness, cough and fever will occur in $\sim 50 \%$ of cases) with abnormal chest radiography (the commonest finding will be pulmonary infiltrates). 2) Investigations should include arterial blood gas analysis, since hypoxia is likely, and pulmonary function tests. Lung function will be abnormal in the majority of patients, with a restrictive pattern being more common than an obstructive pattern although both types of pattern may feature. A full blood count will show a peripheral eosinophilia in approximately half of all cases. 3) If a diagnosis of pulmonary eosinophilia is suspected the prognosis appears good. With a clinical picture of fibrosing alveolitis, the ultimate prognosis appears poorer. 4) Although lung biopsy was performed in >one-third and BAL in just under a quarter of patients it appears that neither histological confirmation of a diagnosis nor BAL findings contribute to the management of patients. The authors would argue that lung biopsy and BAL play little or no role in the management of these patients other than for the exclusion of other conditions e.g. opportunistic infections. If, however, the diagnosis of sulphasalazine lung disease is in doubt and lung histology is required, thorascopic biopsy has been shown to have less morbidity and mortality than open lung biopsy in recent reports $[83,84]$. 5) A trial of systemic steroid therapy should be considered if the patient's symptoms do not resolve within a short time despite sulphasalazine withdrawal and especially if a diagnosis of fibrosing alveolitis is suspected or if the patient is seriously ill. The evidence for the initial use of corticosteroids in the management of all cases of suspected sulphasalazine lung toxicity has not been borne out in this study.

Acknowledgements. The authors would like to thank S. Pinnington and T. Olley for their assistance with translations.

\section{References}

1. Pinals RS, Kaplan SB, Lawson JG, Hepburn B. Sulfasalazine in rheumatoid arthritis. A double-blind, placebo-controlled trial. Arthritis Rheum 1986; 29: 1427-1434. 
2. Dougados M, Combe B, Cantagrel A, et al. Combination therapy in early rheumatoid arthritis: a randomised, controlled, double blind 52 week clinical trial of sulphasalazine and methotrexate compared with the single components. Ann Rheum Dis 1999; 58: 220-225.

3. Emery P. Therapeutic approaches for early rheumatoid arthritis. How early? How aggressive? B J Rheum 1995; 34: Suppl. 2, 87-90.

4. Collins JR. Adverse reactions to salicylazosulfapyridine (azulfidine) in the treatment of ulcerative colitis. South Med J 1968; 61: 354-358.

5. Editorial: Sulphasalazine-induced lung disease. Lancet 1974; 2: 504-505.

6. Camus P. Respiratory disease induced by drugs. Eur Respir J 1997; 10: 260-264.

7. Foucher P, Biour M, Blayac JP, et al. Drugs that may injure the respiratory system. Eur Respir J 1997; 10: 265-279.

8. Case records of the Massachusetts General Hospital. Weekly clinicopathological exercises. Case 12-1993. A 44-year old man with pulmonary disease and proctitis. N Engl J Med 1993; 328: 869-876.

9. Cazzadori A, Braggio P, Bontempini L. Salazopyrininduced eosinophilic pneumonia. Respiration 1985; 47: $158-160$.

10. Davies D, MacFarlane A. Fibrosing alveolitis and treatment with sulphasalazine. Gut 1974; 15: 185-188.

11. Leino R, Liippo K, Ekfors T. Sulphasalazine-induced reversible hypersensitivity pneumonitis and fatal fibrosing alveolitis: report of two cases. J Intern Med 1991; 229: 553-556.

12. Moseley RH, Barwick KW, Dobuler K, DeLuca VA Jr. Sulfasalazine-induced pulmonary disease. Dig Dis Sci 1985; 30: 901-904.

13. Sigvaldason A, Sorenson S. Interstitial pneumonia due to sulfasalazine. Eur J Respir Dis 1983; 64: 229 233.

14. Matek W, Rosch W, Becker V. Pathological changes in lungs and liver after therapy of ulcerative colitis. Fortschr Med 1980; 98: 491-496.

15. Williams T, Eidus L, Thomas P. Fibrosing alveolitis, bronchiolitis obliterans, and sulfasalazine therapy. Chest 1982; 81: 766-768.

16. Bargon J, Rust M, Kardos P, Schneider M, MeierSydow J. Salazosulfapyridine-induced eosinophilic pneumonia with pulmonary and cutaneous epithelioid cell granulomatosis in Sjogren syndrome. Pneumologie 1990; 44: 744-750.

17. Hamadeh MA, Atkinson J, Smith LJ. Sulfasalazineinduced pulmonary disease. Chest 1992; 101: 1033-1037.

18. Sullivan SN. Sulfasalazine lung. Desensitization to sulfasalazine and treatment with acrylic coated 5-ASA and azodisalicylate. J Clin Gastroenterol 1987; 9: 461463.

19. Tydd TF. Sulphasalazine lung. Med J Aust 1976; 1: $570-573$.

20. Wang KK, Bowyer BA, Fleming CR, Schroeder KW. Pulmonary infiltrates and eosinophilia associated with sulfasalazine. Mayo Clin Proc 1984; 59: 343-346.

21. Yamakado S, Yoshida Y, Yamada T, Kishida T, Kobayashi M, Nomura T. Pulmonary infiltration and eosinophilia associated with sulfasalazine therapy for ulcerative colitis: a case report and review of literature. Intern Med 1992; 31: 108-113.

22. Moss SF, Ind PW. Time course of recovery of lung function in sulphasalazine-induced alveolitis. Respir Med 1991; 85: 73-75.
23. Salerno SM, Ormseth EJ, Roth BJ, Meyer CA, Christensen ED, Dillard TA. Sulfasalazine pulmonary toxicity in ulcerative colitis mimicking clinical features of Wegener's granulomatosis. Chest 1996; 110: 556559.

24. Valcke Y, Pauwels R, Van der Straeten M. Bronchoalveolar lavage in acute hypersensitivity pneumonitis caused by sulfasalazine. Chest 1987; 92: 572-573.

25. Farre JM, Perez T, Hautefeuille P, Tonnel F, Duquesnoy B, Delcambre B. Eosinophil pleuritis induced by salazosulfapyridine. Presse Med 1989; 18: 987-988.

26. Thomas P, Seaton A, Edwards J. Respiratory disease due to sulphasalazine. Clin Allergy 1974; 4: 41-47.

27. Timmer R, Duurkens VA, van Hees PA. Sulphasalazineinduced eosinophilic pneumonia. Neth J Med 1992; 41: 153-157.

28. Panayiotou BN. Pulmonary infiltrates and eosinophilia associated with sulphasalazine administration. Aust N Z J Med 1991; 21: 348-349.

29. Rosenhall L, Uddenfeldt M. Lung manifestations after salazopyrinine intake. Lakartidningen 1979; 76 : 3923-3924.

30. Scherpenisse J, van der Valk PD, van den Bosch JM, van Hees PA, Nadorp JH. Olsalazine as an alternative therapy in a patient with sulfasalazine-induced eosinophilic pneumonia. J Clin Gastroenterol 1988; 10: 218-220.

31. Jordan A, Cowan RE. Reversible pulmonary disease and eosinophilia associated with sulphasalazine. $J R$ Soc Med 1988; 81: 233-235.

32. Klein HP, Rupp M, Thiele-Fischbach A. Drug-induced alveolitis caused by salazosulfapyridine. Dtsch Med Wochensch 1988; 113: 1239-1241.

33. Baillie J. Sulfasalazine and pulmonary infiltrates. Am J Gastroenterol 1984; 79: 77.

34. Geborek P, Monti M, Sandblad F, Wollheim FA. Acute alveolitis and sulphasalazine in rheumatoid arthritis. Clin \& Exp Rheumatol 1984; 2: 279-280.

35. Jones GR, Malone DN. Sulphasalazine induced lung disease. Thorax 1972; 27: 713-717.

36. Averbuch M, Halpern Z, Hallak A, Topilsky M, Levo Y. Sulfasalazine pneumonitis. Am J Gastroenterol 1985; 80: 343-345.

37. Berliner S, Neeman A, Shoenfeld Y, et al. Salazopyrininduced eosinophilic pneumonia. Respiration 1980; 39: 119-120.

38. da Cunha B, Anker N. Salazosulfapyridine-induced lung disease. Ugeskr Laeger 1980; 142: 2560-2561.

39. Constantinidis KA. Eosinophilic pneumonia: an unusual side effect of therapy with salicylazosulfapyridine. Chest 1976; 70: 315-316.

40. Kolbe J, Caughey D, Rainer S. Sulphasalazineinduced sub-acute hyper-sensitivity pneumonitis. Respir Med 1994; 88: 149-152.

41. Peters FP, Engels LG, Moers AM. Pneumonitis induced by sulphasalazine. Postgrad Med J 1997; 73: 99-100.

42. Clementz GL, Dolin BJ. Sulfasalazine-induced lupus erythematosus. Am J Med 1988; 84: 535-538.

43. Lorente JA, Perez-Rodriguez E, Badala G, Fogue L. Pulmonary disease induced by salazopyrine coexisting with pulmonary tuberculosis. Med Clin 1989; 93: 476.

44. Trewby PN, Connolly CK. Reversible pulmonary disease and eosinophilia associated with sulphasalazine. J R Soc Med 1988; 81: 558.

45. McKee AL, Rajapaksa A, Kalish PE, Pitchumoni CS. 
Severe interstitial pulmonary fibrosis in a patient with chronic ulcerative colitis. Am J Gastroenterol 1983; 78: 86-89.

46. Teague WG, Sutphen JL, Fechner RE. Desquamative interstitial pneumonitis complicating inflammatory bowel disease of childhood. $J$ Pediatr Gastroenterol Nutr 1985; 4: 663-667.

47. Wellnitz H, Christensen T. Radiographic changes in the chest in a patient with ulcerative colitis treated with salazosulfapyridine. Ugeskr Laeger 1985; 147: 2235-2236.

48. Boyd O, Gibbs AR, Smith AP. Fibrosing alveolitis due to sulphasalazine in a patient with rheumatoid arthritis. Br J Rheumatol 1990; 29: 222-224.

49. Gabazza EC, Taguchi O, Yamakami T, et al. Pulmonary infiltrates and skin pigmentation associated with sulfasalazine. Am J Gastroenterol 1992; 87: 1654-1657.

50. Penalba C, Stambach Y. Salazosulfapyridine responsible of eosinophilic pneumonia. Presse Med 1987; 16: 80 .

51. Assouline PS, Diot P, Janvoie B, et al. Pneumopathy due to sulfasalazopyrine. A case with a challenge test. Rev Mal Respir 1991; 8: 233-236.

52. Manchanda S, Rees PJ. A case of severe reversible lung disease caused by sulphasalazine. Intern J Clin Prac 1999; 53: 233-235.

53. Yaffe BH, Korelitz BI. Sulfasalazine pneumonitis. Am J Gastroenterol 1983; 78: 493-494.

54. Laurent K, De Jonghe M, Flemale A, Kimbimbi P, Defrance P, Gillard C. A new case of hypersensitivity pneumopathy caused by salazopyrine? Rev Pneumol Clin 1985; 41: 340-343.

55. Molina CL, Roche G, Lavaud P, Jeanneret A. Immunoallergic pneumopathy to salazosulfapyridine during ulcerative colitis. Rev Franc Allergol 1979; 19: 181185.

56. Sebastian DJ, Ventura A, Perez de Ayala V, Castellanos D. Hypersensitivity pneumonitis by sulphasalazine. Allergy 1989; 44: 522.

57. Cannon GW. Methotrexate pulmonary toxicity. Rheum Dis Clin North Am 1997; 23: 917-937.

58. Kremer JM, Alarcon GS, Weinblatt ME, et al. Clinical, laboratory, radiographic, and histopathologic features of methotrexate-associated lung injury in patients with rheumatoid arthritis: a multicenter study with literature review. Arthritis Rheum 1997; 40: 1829 1837.

59. Rich MW, Thomas RA. A case of eosinophilic pneumonia and vasculitis induced by diflunisal. Chest 1997; 111: 1767-1769.

60. Burton GH. Rash and pulmonary eosinophilia associated with fenbufen. BMJ 1990; 300: 82-83.

61. Chetty KG, Ramirez MM, Mahutte CK. Druginduced pulmonary edema in a patient infected with human immunodeficiency virus. Chest 1993; 104: 967969.

62. Valdivia E, Hensley G, Leory EP, Wu J, Jaeschke W. Morphology and pathogenesis of desquamative interstitial pneumonitis. Thorax 1977; 32: 7-18.

63. Ford RM. Transient pulmonary eosinophilia and asthma. A review of 20 cases occurring in 5,702 asthma sufferers. Am Rev Respir Dis 1966; 93: 797803.

64. Heffner JE, Sahn SA. Salicylate-induced pulmonary edema. Clinical features and prognosis. Ann Intern Med 1981; 95: 405-409.

65. Steinfort CL, Wiggins J, Sheffield EA, Keal EE.
Alveolitis associated with sulphamethoxypyridazine. Thorax 1989; 44: 310-311.

66. Pascual LF, Calvo BJ, Carrasco MF, SanchezMartinez H. Pneumonitis caused by mesalazine. Arch Bronconeumol 1997; 33: 309-311.

67. Kayser K, Probst F, Gabius HJ, Muller KM. Are there characteristic alterations in lung tissue associated with Crohn's disease? Pathol Res Prac 1990; 186: 485490.

68. Puntis JW, Tarlow MJ, Raafat F, Booth IW. Crohn's disease of the lung. Arch Dis Child 1990; 65: 12701271.

69. Gibb WR, Dhillon DP, Zilkha KJ, Cole PJ. Bronchiectasis with ulcerative colitis and myelopathy. Thorax 1987; 42: 155-156.

70. Higenbottam T, Cochrane GM, Clark TJ, Turner D, Millis R, Seymour W. Bronchial disease in ulcerative colitis. Thorax 1980; 35: 581-585.

71. Swinburn CR, Jackson GJ, Cobden I, Ashcroft T, Morritt GN, Corris PA. Bronchiolitis obliterans organising pneumonia in a patient with ulcerative colitis. Thorax 1988; 43: 735-736.

72. Isenberg JI, Goldstein H, Korn AR, Ozeran RS, Rosen V. Pulmonary vasculitis-an uncommon complication of ulcerative colitis. Report of a case. $N$ Eng J Med 1968; 279: 1376-1377.

73. Rogers BH, Clark LM, Kirsner JB. The epidemiologic and demographic characteristics of inflammatory bowel disease: an analysis of a computerized file of 1400 patients. J Chron Dis 1971; 24: 743-773.

74. Balestra DJ, Balestra ST, Wasson JH. Ulcerative colitis and steroid-responsive, diffuse interstitial lung disease. A trial of $\mathrm{n}=1 . J A M A 1988 ; 260$ : 62-64.

75. Sargent D, Sessions JT, Fairman RP. Pulmonary vasculitis complicating ulcerative colitis. South Med J 1985; 78: 624-625.

76. Kraft SC, Earle RH, Roesler M, Esterly JR. Unexplained bronchopulmonary disease with inflammatory bowel disease. Arch Intern Med 1976; 136: $454-459$.

77. Butland RJ, Cole P, Citron KM, Turner-Warwick M. Chronic bronchial suppuration and inflammatory bowel disease. $Q J$ Med 1981; 50: 63-75.

78. Camus P, Piard F, Ashcroft T, Gal AA, Colby TV. The lung in inflammatory bowel disease. Medicine 1993; 72: 151-183.

79. Spira A, Grossman R, Balter M. Large airway disease associated with inflammatory bowel disease. Chest 1998; 113: 1723-1726.

80. Sartor RB. Pathogenetic and clinical relevance of cytokines in inflammatory bowel disease. Immunol Res 1991; 10: 465-471.

81. Eade OE, Smith CL, Alexander JR, Whorwell PJ. Pulmonary function in patients with inflammatory bowel disease. Am J Gastroenterol 1980; 73: 154-156.

82. Douglas JG, McDonald CF, Leslie MJ, Gillon J, Crompton GK, McHardy GJ. Respiratory impairment in inflammatory bowel disease: does it vary with disease activity? Respir Med 1989; 83: 389-394.

83. Ayed AK, Raghunathan R. Thoracoscopy versus open lung biopsy in the diagnosis of interstitial lung disease: a randomised controlled trial. $J R$ Coll Surg Edinb 2000; 45: 159-163.

84. Martin T, Larraga R, Badorrey I, et al. Videothoracoscopy versus thoracotomy in the diagnosis of diffuse interstitial disease. Arch Bronconeumol 1997; 33: 341345 . 